\title{
Organocuprates Initiated Anionic Living Polymerization of tert-Butyl Methacrylate
}

\author{
Seigou Kawaguchi, ${ }^{\dagger}$ Eiji Nomura, ${ }^{\dagger \dagger}$ and Koichi Ito ${ }^{\dagger}$ \\ Department of Materials Science, Toyohashi University of Technology, \\ Tempaku-cho, Toyohashi 441-8580 Japan
}

(Received September 24, 1997)

\begin{abstract}
We report organocuprates initiated anionic polymerizations of various $\alpha, \beta$-unsaturated ester monomers in tetrahydrofuran (THF) under various conditions. It was found that catalysts prepared by reaction of CuI with methyllithium (MeLi) very effectively cause the polymerization of meth(acrylate) monomers. At molar ratio of [MeLi] to [CuI] higher than 2 the polymerization of $t$-butyl methacrylate (TBMA) proceeded quantitatively in THF at $0-45^{\circ} \mathrm{C}$ to afford high molecular weight poly( $t$-butyl methacrylate) (PTBMA) with extremely narrow molecular weight distribution (MWD) $\left(M_{w} / M_{n}=1.0_{5}-\right.$ $\left.1.1_{7}\right)$. Initiator efficiency was less than $10 \%$ and highest at about $[\mathrm{MeLi}] /[\mathrm{CuI}]=4.0$. The post-polymerization proved the livingness of the polymerization of TBMA caused by lithium methylcuprate in THF at $0{ }^{\circ} \mathrm{C}$. The active species for the polymerization of TBMA was thought to be higher cuprate, such as $\mathrm{Li}_{2} \mathrm{Cu}\left(\mathrm{CH}_{3}\right)_{3}$. For the polymerizations of other methacrylates and $t$-butyl acrylate lithium methylcuprate initiators effectively afforded the polymers but with very broad MWD.

KEY WORDS Organocuprates / Living Polymerization / tert-Butyl Methacrylate /
\end{abstract}

Organocuprates are appreciably used in synthetic organic chemistry because of their ability to give very high regioselectivity in conjugate addition reactions to various $\alpha, \beta$-unsaturated esters and ketones. ${ }^{1}$ Their use as an initiator in the polymerization of analogous vinylic monomers is, thus, of interest.

Organocopper compounds $(\mathrm{RCu})$, prepared by reaction of $\mathrm{CuI}$ with stoichiometric amount of alkyllithium, have been reported as polymerization initiators. The first work on the polymerization of vinyl monomers was reported by Bawn and Whitby ${ }^{2}$ in 1960, who studied free-radical polymerizations of styrene and acrylonitrile in the presence of $\mathrm{RCu}(\mathrm{I})$ as a catalyst. Ikariya and Yamamoto $^{3}$ reported that an isolated complex of methyl(trialkylphosphine)copper(I) caused the polymerizations of acrylonitrile and methyl methacrylate (MMA). Lithium organocuprates $\left(\mathrm{R}_{2} \mathrm{CuLi}\right)$, prepared by the reactions of $\mathrm{CuI}$ and two equivalents of alkyllithium, are normally used in stoichiometric amounts in addition reaction, while polymeric products and low molecular weight oligomers have been found as by-products. However, there are few reports where cuprates have been consciously used as ionic polymerization initiators. ${ }^{4,5}$ Saegusa et al. reported vinyl polymerization of acrylonitrile, methyl acrylate and MMA using cyclopentadienylcopper(I) complexes ${ }^{6}$ and $\mathrm{Cu}_{2} \mathrm{O}$-isonitrile system. ${ }^{7}$ It was shown by Grigonis et al. ${ }^{8}$ that benzoxyethyl methacrylate polymerization initiated with lithium di$n$-butylcuprate $\left((n-\mathrm{Bu})_{2} \mathrm{CuLi}\right)$ in toluene affords highly isotactic polymers $(5 \%$ syndiotactic, $15 \%$ heterotactic, and $80 \%$ isotactic triad contents). Han et al. ${ }^{9}$ reported $(n-\mathrm{Bu})_{2} \mathrm{CuLi}$ to be an effective initiator for $\alpha, \beta$-unsaturated monomers, MMA, acrylonitrile, acrolein, and $N$ acryloylpyrrolidone to afford highly isotactic polymers in toluene. They, however, did not report any evidence related to the molecular weight distribution (MWD) of the polymers and the possibility that the reaction may proceed in a living manner. Day et al. ${ }^{10}$ demonstrated that the polymerizations of MMA initiated with lithium $n$-butylcyanocuprate and $(n-\mathrm{Bu})_{2} \mathrm{CuLi}$ at $-78^{\circ} \mathrm{C}$ proceed in a living manner to afford poly(methyl methacrylate) (PMMA) but with very broad MWD $\left(M_{w} / M_{n}=\right.$ $1.5-1.8)$. The initiator efficiency $(f)$ was found to be less than $4 \%$.

Dimonie et al. ${ }^{11}$ have recently carried out a kinetic study on the polymerization of MMA using several types of organocuprates. They prepared syndiotactic-rich PMMA of $M_{w} / M_{n}=1.2-2.0$ at $-30--10^{\circ} \mathrm{C}$, with relatively high $f$ such as $30-100 \%$. We became interested independently in the fact that Lewis acid-mediated organocopper reagents $\left(n-\mathrm{Bu}_{2} \mathrm{CuLi} / \mathrm{AlCl}_{3}\right)$ reacted regioselectively in 1,4-addition with an electron deficient olefin, diethyl fumarate. ${ }^{12}$ This monomer could not be polymerized using anionic initiators. ${ }^{13} \mathrm{We}$ thought that by optimizing the conditions of the polymerization with organocuprates as an initiator, it might be possible to develop a living polymerization of various $\alpha, \beta$ unsaturated esters, including methacrylates, acrylates, fumarates, and crotonates. ${ }^{14}$ The reaction scheme is shown in Scheme 1. We first investigated the organocuprate initiated polymerization of $t$-butyl methacrylate (TBMA), and applied it to the polymerization of several types of $\alpha, \beta$-unsaturated esters.

\section{EXPERIMENTAL}

\section{Materials}

TBMA and $t$-butyl acrylate (TBA) were supplied from Toagosei Co., Ltd. and diisopropyl fumarate was a gift from NOF Co., Ltd. and MMA, ethyl, isopropyl, iso-

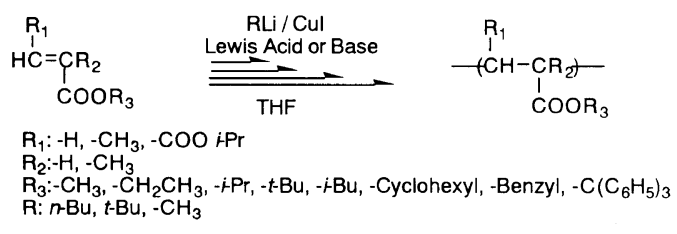

Scheme 1.

\footnotetext{
† To whom all correspondence should be addressed.

${ }^{\dagger \dagger}$ Present address: Kansai Paint Co., Ltd., 4-17-1, Higashiyawata, Hiratsuka 254-8562, Japan.
} 
butyl, cyclohexyl, and benzyl methacrylates, methyl crotonate, diethyl fumarate, and styrene were purchased from Kishida Chemical Co., Ltd. The ester monomers were washed with $5 \%$ aq solution of sodium hydrogen sulfite, $5 \%$ aq sodium hydroxide, followed by $20 \%$ aq sodium chloride to remove hydroquinone inhibitor. The monomers were dried with sodium sulfate overnight and distilled from calcium hydride under a reduced pressure immediately prior to use. Tetrahydrofuran (THF) was refluxed and distilled from the sodium benzophenone solution. Copper iodide (Kojundo Kagaku) was washed by freshly distilled THF with a soxhlet extractor. Methyl-, $n$-butyl-, $t$-butyllithium (Aldrich), lithium 2-thienylcyanocuprate (Aldrich), and dilithium methyl-2-cyanocuprate (Aldrich) were used as received. Other chemicals were purified according to standard purification procedures.

\section{Synthesis of Lithium Organocuprates and Polymerization}

The experiments were carried out in a $50 \mathrm{~mL}$ three-neck reactor fitted with septums. The required amount of $\mathrm{CuI}$ was first introduced into the reactor. The reactor was vacuum-dried for $3 \mathrm{~h}$ at room temperature and filled with argon. Adequate equivalents of alkyllithium in hexane solution were added slowly to $\mathrm{CuI}$ in $\mathrm{THF}$ at $0^{\circ} \mathrm{C}$. The mixture was maintained at $0^{\circ} \mathrm{C}$ for $1 \mathrm{~h}$. The polymerizations were carried out by adding monomers to the reaction mixture at various temperatures $\left(-78-+45^{\circ} \mathrm{C}\right)$ for $30 \mathrm{~min}$. After $30 \mathrm{~min}$, the polymerization was quenched with methanol, and the reaction mixture was poured into a large excess of methanol containing water to precipitate the polymer. The polymers collected by filtration were dried in vacuum. In post-polymerization, by reaction of TBMA and lithium methylcuprate in THF at $0^{\circ} \mathrm{C}$ for $30 \mathrm{~min}$, the prepolymer of TBMA was quantitatively prepared and an aliquot was sampled out for characterization. To the residual reaction mixture at $0^{\circ} \mathrm{C}$, the second feed of TBMA was added and reacted for another $30 \mathrm{~min}$ to complete the further polymerization. Block copolymerizations of TBMA with MMA or
TBA were performed in a similar manner. The polymerizations were also carried out under high-vacuum in an all-glass apparatus equipped with the break-seals. ${ }^{15}$

\section{Measurements}

Size exclusion chromatography (SEC) for the characterization of molecular weight and its distribution was conducted at $40^{\circ} \mathrm{C}$ with JASCO PU980 as a pump, JASCO RI-930 as a refractive index detector, and Shodex $\mathrm{A}-803+\mathrm{A}-804$ and A-804 $+\mathrm{A}-805$ as columns. Elution volume was calibrated with a series of polystyrene (Tosoh Co., Japan) standards. ${ }^{1} \mathrm{H}$ NMR spectra were recorded on a JEOL JNM-GX $270 \mathrm{MHz}$ FT-NMR spectrometer in $\mathrm{CDCl}_{3}$ at room temperature.

\section{RESULTS AND DISCUSSION}

\section{Influence of Types of Alkyllithium}

The results of the polymerization of TBMA using various alkylcuprates are listed in Table I. Lithium homocuprates as initiators caused the polymerization to afford quantitatively poly( $t$-butyl methacrylate) (PTBMA), irrespective of the alkyllithium species used (runs 1-3). In contrast, no polymerization of TBMA occurred when lithium 2-thienylcyanocuprate (LTCC) was used as initiator (run 4). The initiator efficiency $(f)$, calculated assuming lithium dialkylcuprate $\left(\mathrm{R}_{2} \mathrm{CuLi}\right)$ as an active species, and MWD of resulting PTBMA strongly depended on the alkyllithium. The value of $f$ was relatively high $(40-60 \%)$ when using lithium butylcuprates (runs 1, 2), but considerably low $(3.0 \%$ at $0^{\circ} \mathrm{C}$ ) when using lithium methylcuprate (run 3). In the latter system MWD was significantly narrow $\left(M_{w} / M_{n}=\right.$ $\left.1.1_{3}\right)$. The polymerization results using $(n-\mathrm{Bu})_{2} \mathrm{CuLi}$ were almost consistent with those reported by Day et al. ${ }^{10}$ who studied the polymerization of MMA. We note here in particular that the methyllithium-CuI initiator systems gave PTBMA with a narrow MWD and investigated various conditions to optimize the polymerization.

Table I. Polymerizations of TBMA using organocuprates prepared from various alkyllithiums ${ }^{\mathrm{a}}$

\begin{tabular}{ccccccccccc}
\hline Run & $\mathrm{RLi}$ & {$[\mathrm{CuI}] / \mathrm{mmol}$} & {$[\mathrm{RLi}] / \mathrm{mmol}$} & {$[\mathrm{RLi}] /[\mathrm{CuI}]$} & {$[\mathrm{TBMA}] / \mathrm{mmol}$} & $\mathrm{Temp} /{ }^{\circ} \mathrm{C}$ & $\mathrm{Conv} . / \%$ & $M_{n}{ }^{\mathrm{b}} / 10^{3}$ & $M_{w} / M_{n}^{\mathrm{b}}$ & $f / \%{ }^{\mathrm{c}}$ \\
\hline 1 & $n-\mathrm{BuLi}$ & 0.47 & 0.99 & 2.0 & 9.37 & 0 & 97.7 & 7.5 & $1.5_{9}$ & 37 \\
2 & $t-\mathrm{BuLi}$ & 0.42 & 0.85 & 2.0 & 18.0 & -78 & 98.5 & 9.4 & $1.3_{2}$ & $6_{4}$ \\
3 & $\mathrm{MeLi}$ & 0.47 & 1.05 & 2.2 & 9.37 & 0 & 100 & 99 & $1.1_{3}$ & 2.9 \\
4 & $\mathrm{LTCC}$ & - & - & - & 9.37 & 0 & 0 & - & - & 0 \\
\hline
\end{tabular}

${ }^{\text {a }}$ Polymerizations were carried out in $10 \mathrm{~mL}$ THF for $30 \mathrm{~min} .{ }^{\mathrm{b}}$ Determined by SEC calibrated with a series of polystyrene standards. ${ }^{\mathrm{c}}$ Initiator efficiency calculated by the equation, $f(\%)=(W \times$ Conv. $(\%)) /\left([\mathrm{CuI}] \times M_{n}\right)$, where $W$ is weight of TBMA in feed. ${ }^{\mathrm{d}}$ Lithium 2-thienylcyanocuprate, $0.42 \mathrm{mmol}$.

Table II. Polymerizations of TBMA using lithium methylcuprates at various temperatures ${ }^{\mathrm{a}}$

\begin{tabular}{|c|c|c|c|c|c|c|c|c|c|c|}
\hline Run & {$[\mathrm{CuI}] / \mathrm{mmol}$} & {$[\mathrm{MeLi}] / \mathrm{mmol}$} & {$[\mathrm{RLi}] /[\mathrm{CuI}]$} & {$[\mathrm{TBMA}] / \mathrm{mmol}$} & $\mathrm{THF} / \mathrm{mL}$ & $\mathrm{Temp} /{ }^{\circ} \mathrm{C}$ & Conv. $/ \%$ & $M_{n}^{\mathrm{b}} / 10^{3}$ & $M_{w} / M_{n}{ }^{\mathrm{b}}$ & $f / \%^{\mathrm{c}}$ \\
\hline 1 & 0.47 & 0.94 & 2.0 & 9.14 & 10.0 & -78 & 0 & - & - & 0 \\
\hline 2 & 0.47 & 1.93 & 4.1 & 9.14 & 10.0 & -78 & 0 & - & - & 0 \\
\hline 3 & 0.47 & 1.93 & 4.1 & 9.14 & 10.0 & -48 & 4.5 & 14 & $1.9_{6}$ & $0.8_{9}$ \\
\hline 4 & 0.47 & 2.0 & 4.0 & 7.92 & 10.0 & -21 & 100 & 73 & $1.3_{0}$ & 3.3 \\
\hline 5 & 0.47 & 1.88 & 4.0 & 9.14 & 10.0 & 0 & 100 & 44 & $1.0_{5}$ & 6.3 \\
\hline 6 & 0.47 & 1.93 & 4.1 & 9.14 & 10.0 & 22 & 100 & 32 & $\begin{array}{l}1.05 \\
1.0_{7}\end{array}$ & 8.3 \\
\hline 7 & 0.49 & 2.10 & 4.3 & 12.5 & 20.0 & 45 & 99 & 76 & $1.1_{7}$ & 4.7 \\
\hline
\end{tabular}

${ }^{\text {a }}$ Polymerizations were carried out for $30 \mathrm{~min} .{ }^{\mathrm{b}}$ Determined by SEC calibrated with a series of polystyrene standards. ${ }^{\mathrm{c}}$ Initiator efficiency calculated by the equation, $f(\%)=(W \times$ Conv. $(\%)) /\left([\mathrm{CuI}] \times M_{n}\right)$, where $W$ is weight of TBMA in feed. 


\section{Effects of Polymerization Temperature}

Table II shows the polymerization results of TBMA using lithium methylcuprates at various temperatures. The polymerization of TBMA did not occur at $-78^{\circ} \mathrm{C}$ (runs 1,2 ) but did occur slowly at $-48^{\circ} \mathrm{C}$ to afford PTBMA with very broad MWD $\left(M_{w} / M_{n}=1.9_{6}\right)$ (run 3). At $-21^{\circ} \mathrm{C}$, the polymerization proceeded to quantitatively afford PTBMA but with relatively broad MWD $\left(M_{w} / M_{n}=1.3_{0}\right)$. It should be noted, however, that above $0^{\circ} \mathrm{C}$ the polymerizations afford PTBMA with very narrow MWDs (runs 5-7) and the initiator efficiency increases with temperature up to $22^{\circ} \mathrm{C}$. Even at $45^{\circ} \mathrm{C}$, the polymerization proceeded quantitatively to afford the polymer with a relatively narrow $\operatorname{MWD}\left(M_{w} / M_{n}=1.1_{7}\right)$ (run 7). ${ }^{16,17}$

\section{Influence of the Ratio of $[\mathrm{MeLi}]$ to $[\mathrm{CuI}]$}

Ashby et al. ${ }^{18,19}$ reported that the composition of lithium methylcuprates varies with solvent, temperature, and molar ratio of methyllithium to $\mathrm{CuI}$, as follows:

$$
\begin{array}{ll}
\mathrm{MeLi} / \mathrm{CuI}=1 \longrightarrow & \mathrm{MeCu} \\
\mathrm{MeLi} / \mathrm{CuI}<2 \longrightarrow & \mathrm{MeCu} \longrightarrow \mathrm{Me}_{3} \mathrm{Cu}_{2} \mathrm{Li} \\
& \mathrm{Me}_{2} \mathrm{CuLi} \\
\mathrm{MeLi} / \mathrm{CuI}=2 \longrightarrow & \mathrm{Me}_{2} \mathrm{CuI} \\
& \mathrm{Me}_{2} \mathrm{CuLi} \\
\mathrm{MeLi} / \mathrm{CuI}>2 \longrightarrow & \mathrm{Me}_{3} \mathrm{CuLi} \\
& \mathrm{MeLi}_{2}
\end{array}
$$

The reactivity of these lithium methylcuprates for alkyl halides decreases in the order, $\mathrm{RLi}>\mathrm{R}_{3} \mathrm{CuLi}_{2}>\mathrm{R}_{2} \mathrm{Cu}$ $\mathrm{Li}>\mathrm{R}_{3} \mathrm{Cu}_{2} \mathrm{Li}>\mathrm{RCu}$, where $\mathrm{R}$ is an alkyl group. ${ }^{18,19}$ Table III shows the polymerization results of TBMA using lithium methylcuprates prepared at various mole ratios of methyllithium to $\mathrm{CuI}$ at $0^{\circ} \mathrm{C}$, together with the results of the control experiments using $\mathrm{MeLi}$ and 1,1-diphenyl-3-methylpentyllithium (DPPL) as initiator. At the molar ratio, $[\mathrm{MeLi}] /[\mathrm{CuI}]$ higher than 2 , the polymerizations of TBMA quantitatively afforded PTBMAs with very narrow MWDs (runs 4-7). The initiator efficiency increased and MWD correspondingly decreased with molar ratio up to about 4 . Compared with the polymerization results using MeLi (run 8) and DPPL (run 9) at $0^{\circ} \mathrm{C}$, one might reasonably expect relatively high regioselectivity and stability of the lithium methylcuprates active chain-end in the polymerization at $0^{\circ} \mathrm{C}$.

In $[\mathrm{MeLi}] /[\mathrm{CuI}]<2.0$, there may exist three methylcuprates in $\mathrm{THF}, \mathrm{MeCu}, \mathrm{Me}_{3} \mathrm{Cu}_{2} \mathrm{Li}$, and $\mathrm{Me}_{2} \mathrm{CuLi}$. Since $\mathrm{MeCu}$ does not cause the polymerization of TBMA (runs 1, 2), $\mathrm{Me}_{3} \mathrm{Cu}_{2} \mathrm{Li}$ and $\mathrm{Me}_{2} \mathrm{CuLi}$ may cause the polymerization. However, initiator efficiency was very low $(f=0.69 \%)$ and the polymer with a broad MWD was obtained (run 3). Therefore, $\mathrm{Me}_{3} \mathrm{Cu}_{2} \mathrm{Li}$ and $\mathrm{Me}_{2}$ $\mathrm{CuLi}$ species are thought not so good to control the polymerization of TBMA in THF at $0^{\circ} \mathrm{C}$

At $[\mathrm{MeLi}] /[\mathrm{CuI}]>2.0$, there are three active species, $\mathrm{Me}_{2} \mathrm{CuLi}, \mathrm{Me}_{3} \mathrm{CuLi}_{2}$, and $\mathrm{MeLi}$ in the following equilibrium. ${ }^{18}$

$$
1 / 4(\mathrm{MeLi})_{4}+1 / 2\left(\mathrm{Me}_{2} \mathrm{CuLi}\right)_{2} \stackrel{K}{\rightleftharpoons} \mathrm{Me}_{3} \mathrm{CuLi}_{2}
$$

Ashby et al. ${ }^{18,19}$ determined, using NMR, the equilibrium constant, $K$ to be $0.12 \mathrm{~L} \mathrm{~mol}^{-1}$ in THF at $-5^{\circ} \mathrm{C}$. Indeed, we confirmed the existence of free methyllithium in $[\mathrm{MeLi}] /[\mathrm{CuI}]>2.0$ by Gilman test. ${ }^{20}$ Since MeLi itself was not a good active species (run 8) in THF at $0^{\circ} \mathrm{C}$, we suppose that the active species of the polymerization of TBMA is $\mathrm{Me}_{3} \mathrm{CuLi}_{2}$. According to Ashby's formulation, we calculated the concentration of $\mathrm{Me}_{3} \mathrm{CuLi}_{2}$ and thereby, effective initiator efficiency $\left(f_{\text {eff }}\right)$, based on the assumption that $\mathrm{Me}_{3} \mathrm{CuLi}_{2}$ is an active species for the polymerization of TBMA at $0^{\circ} \mathrm{C}$. The values of $f_{\text {eff }}$ are listed in Table III. Interestingly, $f_{\text {eff }}$ changed very little with methyllithium concentration to lie around $55 \pm 9 \%$, except for run 7 . More data are needed to conclude what is actually an active species of the polymerization of TBMA and why $f_{\text {eff }}$ decreases at $[\mathrm{MeLi}] /[\mathrm{CuI}]$ higher than 6 .

Since it is of great importance to estimate the stability of the active chain end for proof of the livingness of polymerization, post-polymerization was carried out. After the first polymerization of TBMA with lithium methylcuprate $([\mathrm{MeLi}] /[\mathrm{CuI}]=4.0)$ in $\mathrm{THF}$ at $0^{\circ} \mathrm{C}$ for $30 \mathrm{~min}$, the second feed of TBMA was added to the reaction mixture and reacted for another $30 \mathrm{~min}$ to complete the polymerization. The postpolymer was

\begin{tabular}{|c|c|c|c|c|c|c|c|c|c|}
\hline Run & {$[\mathrm{CuI}] / \mathrm{mmol}$} & {$[\mathrm{MeLi}] / \mathrm{mmol}$} & {$[\mathrm{RLi}] /[\mathrm{CuI}]$} & {$[$ TBMA $] / \mathrm{mmol}$} & Conv./\% & $M_{n}^{\mathrm{b}} / 10^{3}$ & $M_{w} / M_{n}{ }^{\mathrm{b}}$ & $f / \%^{\mathrm{c}}$ & $f_{\text {eff. }} / \%^{\mathrm{d}}$ \\
\hline 1 & 0.47 & 0.40 & 0.85 & 9.14 & 0 & - & - & 0 & - \\
\hline 2 & 0.47 & 0.53 & 1.1 & 9.14 & 0 & - & - & 0 & - \\
\hline 3 & 0.47 & 0.76 & 1.62 & 13.15 & 84.2 & $48_{5}$ & $1.3_{4}$ & $0.6_{9}$ & - \\
\hline 4 & 0.47 & 1.05 & 2.2 & 9.37 & 100 & 99 & $1.1_{3}^{4}$ & 2.9 & $4_{6}$ \\
\hline 5 & 0.47 & 1.45 & 3.1 & 9.14 & 100 & 72 & $1.1_{0}$ & 3.9 & $6_{2}$ \\
\hline 6 & 0.47 & 1.88 & 4.0 & 9.14 & 100 & 44 & $1.0_{5}$ & 6.3 & $5_{6}$ \\
\hline 7 & 0.47 & 2.89 & 6.1 & 9.14 & 100 & 67 & $1.1_{2}$ & 4.2 & 5.7 \\
\hline $8^{e}$ & 0.0 & $0.43(\mathrm{MeLi})$ & - & 9.14 & 7.3 & $47_{3}$ & $1.5_{0}$ & $0.0_{5}$ & - \\
\hline $9^{\mathrm{e}}$ & 0.0 & 1.30 (DPPL) & - & 9.14 & 98 & 3.4 & $1.4_{6}$ & 29 & - \\
\hline
\end{tabular}
quantitatively obtained after quenching. From the SEC chromatogram of the postpolymer shown in Figure 1, the peak of the prepolymer disappeared completely and

Table III. Polymerizations of TBMA using lithium methylcuprates prepared at various $[\mathrm{MeLi}] /[\mathrm{CuI}]$ ratios at $0^{\circ} \mathrm{C}^{\mathrm{a}}$

${ }^{a}$ Polymerizations were carried out in $10 \mathrm{~mL}$ THF for $30 \mathrm{~min} .{ }^{\mathrm{b}}$ Determined by SEC calibrated with polystyrene standards. ${ }^{\mathrm{c}}$ Initiator efficiency calculated by the equation, $f(\%)=(W \times$ Conv. $(\%)) /\left([\mathrm{CuI}] \times M_{n}\right)$, where $W$ is weight of TBMA in feed. ${ }^{\mathrm{d}}$ Effective initiator efficiency calculated by the equation, $f_{\text {eff }}(\%)=(W \times$ Conv. $(\%)) /\left(\left[\mathrm{Me}_{3} \mathrm{CuLi}_{2}\right] \times M_{n}\right)$, where $\left[\mathrm{Me}_{3} \mathrm{CuLi}_{2}\right]$ was calculated using equilibrium constant, $K=0.12 \mathrm{~L} \mathrm{~mol}{ }^{-1}$ in THF at $-5^{\circ} \mathrm{C}$, reported by Ashby and Watkins. ${ }^{18}{ }^{\mathrm{e}}$ Control experiments with MeLi and 1,1-diphenyl-3-methylpentyllithium (DPPL) as initiator in THF at $0^{\circ} \mathrm{C}$. 
the peak of the postpolymer shifted to the higher molecular weight side. The resulting postpolymer possessed the expected molecular weight and a narrow MWD $\left(M_{w} / M_{n}=1.0_{8}\right)$. Consequently, it is evident that the propagating end produced by the cuprate initiator is stable in THF at $0^{\circ} \mathrm{C}$ at least for $30 \mathrm{~min}$ and initiates further polymerization of TBMA.

\section{Effects of Lewis Acids and Bases}

One characteristic of Lewis acid and base mediated organocuprates is the effective 1,4-addition with sterically hindered $\alpha, \beta$-unsaturated esters and ketones with which normal organocuprates do not react. ${ }^{12,21,22}$ Therefore, we investigated the effects of Lewis acids and bases on the polymerization of TBMA initiated by lithium methylcuprates. The polymerization results are presented in Table IV. Contrary to our expectation, the polymerizations failed to occur in the presence of Lewis acid (runs 1-3), except for triethylaluminum (run 4). The addition of Lewis bases caused polymerization but initiator efficiency decreased and MWD broadened (runs 5 -8). Therefore, we could not find any positive effect of the additives on the polymerization of TBMA at $0^{\circ} \mathrm{C}$.

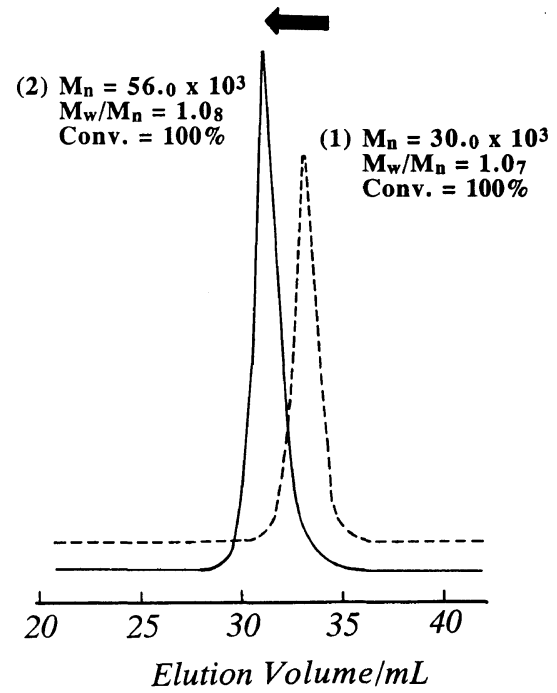

Figure 1. SEC curves of PTBMA obtained at $0^{\circ} \mathrm{C}$ : first polymerization (broken lines) (1), $M_{n}$ (obsd) $=30 \times 10^{3}, M_{w} / \mathrm{M}_{n}=1.0_{7},[\mathrm{MeLi}] /$ $[\mathrm{CuI}]=4.0$, Conv. $=100 \%, f=6.0 \%$; second polymerization (solid line) (2), $M_{n}$ (obsd) $=56 \times 10^{3}, M_{w} / M_{n}=1.0_{8}$, Conv. $=100 \%, M_{n}$ (calcd)= $57 \times 10^{3}$ (the second monomer was added $30 \mathrm{~min}$ after the first addition).

\section{Polymerization of $\alpha, \beta$-Unsaturated Esters}

The polymerization results of various $\alpha, \beta$-unsaturated esters initiated by lithium organocuprates in THF are listed in Table $\mathrm{V}$. When [RLi]/[CuI] is higher than 2, the initiators initiated the polymerization of methyl, ethyl, isopropyl, isobutyl, cyclohexyl, benzyl, and triphenylmethyl methacrylates to give polymers with broad MWDs $\left(M_{w} / M_{n}=1.5-2.2\right)$ (runs $\left.1-12\right)$. The initiators also effectively initiated the polymerization of TBA and styrene to afford polymers with very broad MWDs $\left(M_{w} / M_{n}=1.7-2.7\right)$ (runs $\left.13-16,24\right)$. The cuprate initiators, however, could not initiate the polymerizations of methyl crotonate, and diethyl and diisopropyl fumarates, irrespective of the presence or absence of Lewis acid (runs 17-22). The feature to be noted in the polymerizations of methacrylates other than TBMA is that polymerizations proceeded with relatively higher initiator efficiency (e.g., for MMA, $f=27 \%$ at $0^{\circ} \mathrm{C}$, run 4), implying that the other cuprates presented in eq 3-5 may also be active species for the polymerization of MMA. The tacticity of PMMA prepared in THF at $0^{\circ} \mathrm{C}$ (run 4 in Table $\mathrm{V}$ ) was estimated to be $1.8 \%$ isotactic, $38.7 \%$ heterotactic, and $59.5 \%$ syndiotactic in triad, by ${ }^{1} \mathrm{H}$ NMR measurement.

Syntheses of block copolymer of TBMA with MMA or TBA were carried out by the sequential polymerization of TBMA followed by MMA or TBA in THF at $0^{\circ} \mathrm{C}$. From the SEC chromatogram of PTBMA-block-PMMA shown in Figure 2(a), it was observed that the peak of prepolymer, PTBMA disappeared and the peak of the block copolymer appeared at the higher molecular weight side, in addition to the appearance of a new peak in the lower molecular weight side. The polymer in the region of lower molecular weight side was considered the PMMA homopolymer most probably formed by the initiation with $\mathrm{Me}_{2} \mathrm{CuLi}$ remaining in the reaction medium. We successfully carried out peak separation of the SEC chromatogram into two components, high molecular weight $\left(M_{n}=99 .{ }_{5} \times 10^{3}, M_{w} / M_{n}=1.2_{1}\right)$ and low molecular weight $\left(M_{n}=52 \times 10^{3}, M_{w} / M_{n}=1.3_{2}\right)$, respectively.

The ratio of MMA successfully incorporated into block copolymer to total MMA polymerized, $x$, is calculated by

Table IV. Polymerizations of TBMA using lithium methylcuprates in the presence of Lewis acid and base at $0^{\circ} \mathrm{C}^{\mathrm{a}}$

\begin{tabular}{|c|c|c|c|c|c|c|c|}
\hline Run & {$[\mathrm{CuI}] / \mathrm{mmol}$} & {$[\mathrm{RLi}] /[\mathrm{CuI}]$} & Additives & Conv./\% & $M_{\mathrm{n}}^{\mathrm{b}} / 10^{3}$ & $M_{w} / M_{n}{ }^{b}$ & $f / \%^{\mathrm{c}}$ \\
\hline 1 & 0.47 & 2.2 & $\mathrm{BF}_{3} \mathrm{OEt}_{2}$ & 0 & - & - & 0 \\
\hline 2 & 0.47 & 2.2 & $\mathrm{Me}_{3} \mathrm{SiCl}$ & 0 & - & - & 0 \\
\hline 3 & 0.47 & 2.2 & $\mathrm{AlCl}_{3}$ & 0 & - & - & 0 \\
\hline 4 & 0.47 & 2.2 & $\mathrm{AlEt}_{3}$ & 64 & $29_{6}$ & $1.3_{1}$ & $0 .{ }_{6}$ \\
\hline 5 & 0.47 & 2.2 & $\mathrm{Ph}_{3} \mathrm{P}$ & 85 & $14_{0}$ & $1.1_{4}$ & 1.7 \\
\hline 6 & 0.47 & 2.2 & TMEDA & 100 & $40_{5}$ & $1.1_{2}$ & 0.7 \\
\hline 7 & 0.47 & 4.1 & TMEDA & 95 & 70 & $1.2_{9}$ & 3.8 \\
\hline 8 & 0.47 & 2.2 & $2,2^{\prime}$-Bipyridine & 100 & $59_{9}$ & $1.3_{3}$ & 0.5 \\
\hline
\end{tabular}

${ }^{\text {a }}$ Polymerizations were carried out in $10 \mathrm{~mL}$ THF for $30 \mathrm{~min}$. [TBMA] $=9.37 \mathrm{mmol}$. The catalysts of $0.47 \mathrm{mmol}$ were added to the initiator solution. ${ }^{\mathrm{b}}$ Determined by SEC calibrated with polystyrene standards. ' Initiator efficiency calculated by the equation, $f(\%)=(W \times$ Conv. $(\%)) /$ $\left([\mathrm{CuI}] \times M_{n}\right)$, where $W$ is weight of TBMA in feed. 
S. Kawaguchi, E. Nomura, and K. Ito

Table V. Polymerizations of $\alpha, \beta$-unsaturated esters, $\left.\mathrm{CH}\left(\mathrm{R}_{1}\right)=\mathrm{C}_{(\mathrm{R}}\right) \mathrm{COOR}_{3}$ using lithium methylcuprates ${ }^{\mathrm{a}}$

\begin{tabular}{|c|c|c|c|c|c|c|c|c|c|c|c|}
\hline Run & $\mathrm{R}_{1}$ & $\mathrm{R}_{2}$ & $\mathrm{R}_{3}$ & {$[\mathrm{M}] / \mathrm{mmol}$} & $\mathrm{CuI} / \mathrm{mmol}$ & {$[\mathrm{MeLi}] /[\mathrm{CuI}]$} & Temp. $/{ }^{\circ} \mathrm{C}$ & Conv./\% & $M_{n}^{\mathrm{b}} / 10^{3}$ & $M_{w} / M_{n}{ }^{\mathrm{b}}$ & $f / \%^{\mathrm{c}}$ \\
\hline 1 & $\mathrm{H}$ & $\mathrm{CH}_{3}$ & $\mathrm{CH}_{3}{ }^{\mathrm{d}}$ & 16 & 0.47 & 2.0 & 0 & 0 & - & - & 0 \\
\hline 2 & $\mathrm{H}$ & $\mathrm{CH}_{3}$ & $\mathrm{CH}_{3}$ & 16 & 0.47 & 2.3 & 0 & 56.3 & 31 & $1.5_{4}$ & 6.2 \\
\hline 3 & $\mathrm{H}$ & $\mathrm{CH}_{3}$ & $\mathrm{CH}_{3}$ & 14.1 & 0.47 & 4.1 & -58 & 21.4 & $18_{2}$ & $1.4_{3}$ & $0.3_{5}$ \\
\hline 4 & $\mathrm{H}$ & $\mathrm{CH}_{3}$ & $\mathrm{CH}_{3}$ & 16.5 & 0.47 & 4.1 & 0 & 89.3 & $11_{7}$ & $1.9_{4}$ & 27 \\
\hline 5 & $\mathrm{H}$ & $\mathrm{CH}_{3}$ & $\mathrm{CH}_{3}$ & 11.8 & 0.47 & 4.1 & 19 & 86.0 & 5.5 & $1.7_{8}$ & $3_{9}$ \\
\hline 6 & $\mathrm{H}$ & $\mathrm{CH}_{3}$ & Ethyl & 13.2 & 0.47 & 3.9 & 0 & $80_{0}$ & 6.5 & $2.1_{6}^{\circ}$ & 39 \\
\hline 7 & $\mathrm{H}$ & $\mathrm{CH}_{3}$ & $i-\operatorname{Pr}$ & 14.1 & 0.47 & 4.1 & 0 & 96.0 & - & - & - \\
\hline 8 & $\mathrm{H}$ & $\mathrm{CH}_{3}$ & $i$-Bu & 10.3 & 0.47 & 3.7 & 0 & 95.0 & 13 & $2.1_{5}$ & $2_{3}$ \\
\hline 9 & $\mathrm{H}$ & $\mathrm{CH}_{3}$ & $\mathrm{CyH}^{\mathrm{e}}$ & 12.1 & 0.47 & 4.07 & 0 & $98 \cdot ._{0}$ & - & - & - \\
\hline 10 & $\mathrm{H}$ & $\mathrm{CH}_{3}$ & Benzyl & 11.3 & 0.47 & 4.98 & 0 & 74.3 & - & - & - \\
\hline 11 & $\mathrm{H}$ & $\mathrm{CH}_{3}$ & $\mathrm{C}(\mathrm{Ph})_{3}$ & 11.3 & 0.47 & 2.0 & 0 & 0 & - & - & - \\
\hline 12 & $\mathrm{H}$ & $\mathrm{CH}_{3}$ & $\mathrm{C}(\mathrm{Ph})_{3}$ & 11.3 & 0.47 & 4.0 & 0 & 98.5 & - & - & - \\
\hline 13 & $\mathrm{H}$ & $\mathrm{H}$ & $t-\mathrm{Bu}$ & 10.4 & 0.47 & 1.9 & 0 & 76.8 & 36 & $1.6_{6}$ & 6.6 \\
\hline 14 & $\mathrm{H}$ & $\mathrm{H}$ & $t-\mathrm{Bu}^{\mathrm{f}}$ & 22.1 & 0.36 & 2.0 & -78 & 25.9 & $14_{30}$ & $1.7_{2}$ & 0.1 \\
\hline 15 & $\mathrm{H}$ & $\mathrm{H}$ & $t-\mathrm{Bu}$ & 10.4 & 0.47 & 4.1 & 0 & 64.0 & 19.3 & $2.1_{1}$ & 9.9 \\
\hline 16 & $\mathrm{H}$ & $\mathrm{H}$ & $t-\mathrm{Bu}$ & 10.4 & 0.47 & 4.1 & 19 & 53.0 & 12.3 & $2.1_{5}$ & $1_{3}$ \\
\hline 17 & $\mathrm{CH}_{3}$ & $\mathrm{H}$ & $\mathrm{CH}_{3}$ & 14.1 & 0.47 & 2.0 & 0 & 0 & - & - & 0 \\
\hline 18 & $\mathrm{CH}_{3}$ & $\mathrm{H}$ & $\mathrm{CH}_{3}{ }^{\mathrm{g}}$ & 14.1 & - & - & 0 & 0 & - & - & 0 \\
\hline 19 & COOEt & $\mathrm{H}$ & Ethyl & 14.1 & 0.47 & 2.0 & 0 & 0 & - & - & 0 \\
\hline 20 & COOEt & $\mathrm{H}$ & Ethyl ${ }^{\mathrm{h}}$ & 14.1 & - & - & $-78-0$ & 0 . & - & - & 0 \\
\hline 21 & COOEt & $\mathrm{H}$ & Ethyl & 14.1 & 0.47 & 4.0 & 0 & 0 & - & - & 0 \\
\hline 22 & $\mathrm{COO} i-\mathrm{Pr}$ & $\mathrm{H}$ & $i-\operatorname{Pr}$ & 14.1 & 0.47 & 2.0 & 0 & 0 & - & - & 0 \\
\hline 23 & styrene & & & 18.7 & 0.47 & 2.0 & 0 & 0 & - & - & 0 \\
\hline 24 & styrene & & & 18.7 & 0.47 & 4.36 & 0 & 98.0 & 27.0 & $2.6_{5}$ & $1_{5}$ \\
\hline
\end{tabular}

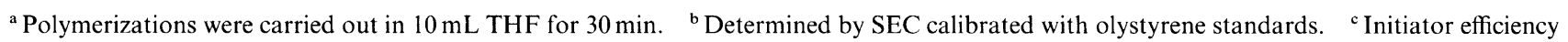
calculated by the equation, $f(\%)=(W \times$ Conv. $(\%)) /\left([\mathrm{CuI}] \times M_{n}\right)$, where $W$ is weight of the monomer in feed. ${ }^{\mathrm{d}} \mathrm{In} 10 \mathrm{~mL}$ toluene. ${ }^{\mathrm{e}}$ Cyclohexyl. ${ }^{\mathrm{f}} \mathrm{THF}=20 \mathrm{~mL} .{ }^{\mathrm{g}}$ Dilithium methyl-2-cyanocuprate, $0.47 \mathrm{mmol} .{ }^{\mathrm{h}} \mathrm{Bu}_{2} \mathrm{CuLi} \cdot \mathrm{BF}_{3}, 0.47 \mathrm{mmol}$.

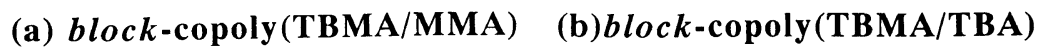

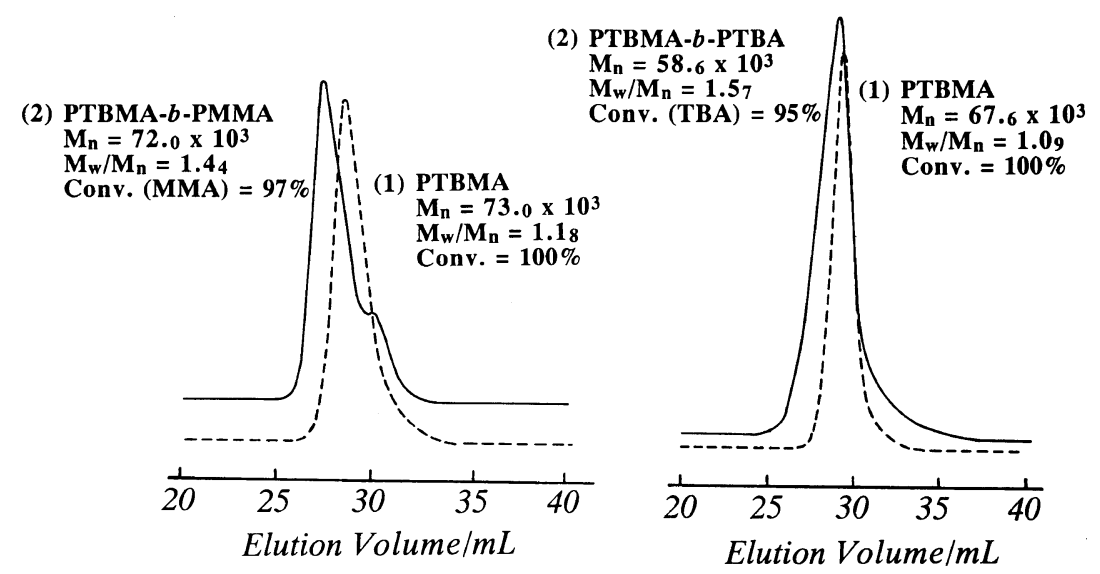

Figure 2. (a) SEC curves of block copolymer of TBMA with MMA: first polymerization of TBMA (broken lines) $(1), M_{n}\left(\right.$ obsd) $=73 \times 10^{3}$, $M_{w} / M_{n}=1.1_{8},[\mathrm{MeLi}] /[\mathrm{CuI}]=4.1_{8}$, Conv. $=100 \%, f=6 ._{4}$; second polymerization of MMA (solid line) $(2), M_{n}(\mathrm{obsd})=72 \times 10^{3}, M_{w} / M_{n}=1.4_{4}$, Conv. $(\mathrm{MMA})=97 \%, M_{n}$ (calcd) $=123 \times 10^{3}$ (the second MMA monomer was added $30 \mathrm{~min}$ after the first addition). (b) SEC curves of block copolymer of TBMA with TBA: first polymerization of TBMA (broken lines) (1), $M_{n}$ (obsd) $=67 .{ }_{6} \times 10^{3}, M_{w} / M_{n}=1.0_{9},[\mathrm{MeLi}] /[\mathrm{CuI}]=4.1_{1}$, Conv. $=100 \%, f=7.8$; second polymerization of TBMA (solid line) (2), $M_{n}$ (obsd) $=58 .{ }_{6} \times 10^{3}, M_{w} / M_{n}=1.5_{7}$, Conv. (TBA) $=95 \%, M_{n}$ $($ calcd $)=112 \times 10^{3}$ (the second TBA monomer was added $30 \mathrm{~min}$ after the first addition).

$$
x(\%)=\frac{S_{\text {PTBMA }-b-\text { PMMA }}\left(\frac{\mathrm{d} n}{\mathrm{~d} c}\right)_{\text {PMMA }} W_{\text {MMA }} \theta_{\text {MMA }}-S_{\text {РMMA }}\left(\frac{\mathrm{d} n}{\mathrm{~d} c}\right)_{\text {РTBMA }} W_{\text {ТВMA }} \theta_{\text {TBMA }}}{S_{\text {PTBMA- } b-\text { PMMA }}\left(\frac{\mathrm{d} n}{\mathrm{~d} c}\right)_{\text {PMMA }} W_{\text {MMA }} \theta_{\text {MMA }}+S_{\text {PMMA }}\left(\frac{\mathrm{d} n}{\mathrm{~d} c}\right)_{\text {PMMA }} W_{\text {MMA }} \theta_{\text {MMA }}} \times 100
$$

where $S$ is the area of SEC chromatogram, $(\mathrm{d} n / \mathrm{d} c)$, the excess refractive index increment in $\mathrm{THF},{ }^{23} \mathrm{~W}$, the weight of monomer in feed, and $\theta$, the conversion, and the subscripts correspond to the respective monomers, polymers, and block copolymer. We determined $x$ to be $61 \%$. In other words, $61 \%$ of MMA is successfully block-copolymerized and $39 \%$ of MMA is polymerized by reinitiation with the cuprates to afford the PMMA homopolymer. $M_{n}$ of the block copolymer is calculated to be $10_{4} \times 10^{3}$, based on the fact that $61 \%$ of MMA is polymerized by the living PTBMA anions. The $M_{n}$ is in good agreement with $M_{n}$ observed for the block 
copolymer. This implies that the broadening of MWD in the homopolymerization of MMA initiated by lithium methylcuprates (Table V), is due to slow initiation rate and/or multiple active species.

On the other hand, from the SEC chromatogram of PTBMA-block-poly(TBA) shown in Figure 2(b) it was deduced that significant termination and propagation reactions with multiple active species may occur during the polymerization of TBA in THF at $0^{\circ} \mathrm{C}$.

This study demonstrates that lithium methylcuprateinitiated polymerizations of TBMA proceed in a living manner in $\mathrm{THF}$ at $0-45^{\circ} \mathrm{C}$. At $[\mathrm{MeLi}] /[\mathrm{CuI}]$ higher than 2 the polymerization afforded PTBMA with very narrow MWD $\left(M_{w} / M_{n}=1.05-1.1_{7}\right)$. The initiator effectively polymerized other methacrylates, TBA, and styrene to afford polymers but with broad MWDs. The active species for the TBMA polymerization was supposed to be $\mathrm{Me}_{3} \mathrm{CuLi}_{2}$. The initiator was not effective for the polymerizations of crotonates and fumarates.

Acknowledgments. The authors thank Dr. T. Ishizone at Tokyo Institute of Technology and Prof. H. Nishiyama at Toyohashi University of Technology for their valuable comments. The authors are indebted to Toagosei Co., Ltd. for TBMA and TBA and to NOF Co., Ltd. for diisopropyl fumarate. S. K. thanks the Ministry of Education, Science, Sports and Culture, Japan for financial support of this work with Grant-in-Aids for the Encouragement of Young Scientists (No. 03750648) and (No. 04750735).

\section{REFERENCES AND NOTES}

1. G. H. Posner, "An Introduction to Synthesis Using Organocopper Reagents," John Wiley \& Sons, Inc., New York, N.Y., 1980.

2. C. E. Bawn and F. J. Whitby, J. Chem. Soc., 3926 (1960).
3. T. Ikariya and A. Yamamoto, J. Organomet. Chem., 72, 145 (1974).

4. H. O. House and W. F. Fisher, J. Org. Chem., 33, 949 (1968).

5. H. O. House and M. J. Umen, J. Am. Chem. Soc., 94, 5495 (1972).

6. T. Saegusa, S. Horiguchi, and T. Tsuda, Macromolecules, 8, 112 (1975).

7. T. Saegusa and S. Horiguchi, Polym. J., 6, 419 (1974).

8. D. E. Gregonis, G. A. Russell, J. D. Andrade, and A. C. deVisser, Polymer, 19, 1279 (1978).

9. Y. K. Han, J. M. Park, and S. K. Choi, J. Polym. Sci., Polym. Chem. Ed., 20, 1549 (1982).

10. P. Day, G. C. Eastmond, T. L. Gilchrist, and P. C. Bulmanpage, Pure Appl. Chem., A29, 545 (1992).

11. M. Dimonie, D. Mardare, S. Coca, T. E. Hogen-Esch, and J. Zoller, Makromol. Chem., Macromol. Symp., 67, 175 (1993).

12. T. Ibuka, T. Aoyagi, K. Kitada, F. Yoneda, and Y. Yamamoto, J. Organomet. Chem., 287, C18 (1985).

13. T. Kitano, A. Ishigaki, G. Uematsu, S. Kawaguchi, and K. Ito, J. Polym. Sci., Polym. Chem. Ed., 25, 979(1987).

14. E. Nomura, S. Kawaguchi, and K. Ito, Polym. Prepr., Jpn., 42, 339 (1993).

15. S. Kawaguchi, T. Takahashi, H. Tajima, Y. Hirose, and K. Ito, Polym. J., 28, 735 (1996).

16. It has been reported that the anionic polymerization of TBMA in $\mathrm{THF}$ proceed in a living manner at $17^{\circ} \mathrm{C}$ when using lithium as a countercation and at $37^{\circ} \mathrm{C}$ when using sodium. ${ }^{17}$

17. T. E. Long, R. D. Allen, and J. E. McGrath, "Recent Advances in Mechanistic and Synthetic Aspects of Polymerization," M. Fontanille and A. Guyot, Ed., NATO ASI Series 215, 1987, p 79; A. H. E. Müller, Makromol. Chem., 482, 2863 (1981).

18. E. C. Ashby and J. J. Watkins, J. Am. Chem. Soc., 99, 5312 (1977).

19. E. C. Ashby and J. J. Lin, J. Org. Chem., 42, 2805 (1977).

20. H. Gilman and F. Schulze, J. Am. Chem. Soc., 47, 2002 (1925).

21. Y. Yamamoto and K. Maruyama, J. Am. Chem. Soc., 100, 3240 (1978).

22. Y. Yamamoto, S. Yamamoto, H. Yatagai, Y. Ishihara, and K. Maruyama, J. Org. Chem., 47, 119 (1982).

23. The refractive index increment of PTBMA and PMMA in THF at $25^{\circ} \mathrm{C}$ was determined to be $0.072_{8}$ and $0.090_{0} \mathrm{~mL} \mathrm{~g}^{-1}$, respectively. 